\title{
EFEITOS DO COMÉRCIO INTERNACIONAL E DE FATORES DE OFERTA NA ESCOLARIDADE DOS TRABALHADORES BRASILEIROS*
}

\author{
Rafael Camargo de Pauli ${ }^{a}$ \\ Luciano Nakabashi ${ }^{b}$ \\ Armando Vaz Sampaio ${ }^{c}$
}

\begin{abstract}
RESUMO: Neste artigo, analisamos as fontes das oscilações na demanda por trabalhadores, de acordo com seus respectivos níveis de escolaridade, com especial ênfase à indústria de transformação brasileira, entre 1994 e 2008. Consideramos duas teorias para explicar essas fontes: o teorema de Heckscher-Ohlin (H-O)e a hipótese do viés de habilidade. $\mathrm{Na}$ análise empírica utilizamos pioneiramente para o Brasil a análise de decomposição ao nível setorial e da firma para verificar qual das teorias refletiria melhor à realidade. Os resultados dão algum suporte à hipótese do viés de habilidade para os trabalhadores com ensino superior completo. Adicionalmente, os resultados apontam que as forças do comércio internacional destacadas pelo teorema de $\mathrm{H}-\mathrm{O}$ têm relevância no caso da economia brasileira. Contudo, verificou-se que o aumento da oferta de trabalhadores com qualificação intermediária foi a principal causa do aumento da escolaridade da força de trabalho da indústria de transformação.
\end{abstract}

PALAVRAS-CHAVE: Indústria de transformação; teorema de Heckscher-Ohlin (H-O); hipótese do viés de habilidade; qualificação dos trabalhadores.

CLASSIFICAÇÃO JEL: J23; J24; J31; L16.

\footnotetext{
Artigo recebido em 21/02/2011 e aprovado em 05/08/2013.

a Mestre em Desenvolvimento Econômico pela Universidade Federal do Paraná (UFPR) e analista de desenvolvimento da Agência de Fomento do Paraná AS. Contato: rafaelcdp@gmail.com.

$b$ Doutor em Economia pelo Centro de Desenvolvimento e Planejamento Regional de Minas Gerais da Universidade Federal de Minas Gerais (CEDEPLAR/UFMG), professor do Departamento de Economia da Faculdade de Economia, Administração e Contabilidade de Ribeirão Preto (FEA-RP/USP). Contato: luciano.nakabashi@gmail.com.

c Doutor em Economia pela Escola Superior de Agricultura Luiz de Queiroz da Universidade de São Paulo (ESALQ/USP) e professor associado do Departamento de Economia da UFPR. Contato: avsampaio@ ufpr.br.
} 


\title{
INTERNATIONAL TRADE, INVESTIMENT IN EDUCATION AND THE BRAZILIAN WORKERS LEVEL OF SCHOOLING
}

\begin{abstract}
In this article, we analyze the causes of the swings in the demand for labor force associated with their level of schooling, with special emphasis on the Brazilian manufacturing industry, in the period 1994-2008. Two theories have been considered to explain the sources of these swings: the Heckscher-Ohlin Theorem (H-O) and the ability bias hypothesis. In the empirical analysis, a sector level decomposition analysis was performed to verify which theory best fit the data. The empirical results give some support to the ability bias hypothesis when higher education labor force sample in used in the empirical analysis. Additionally, we found out that the international trade forces emphasized by the $\mathrm{H}-\mathrm{O}$ Theorem are relevant in the Brazilian economy. However, we also found that the increase of intermediate level of education labor force supply was the main cause of schooling increase in the manufacturing industry labor force.
\end{abstract}

KEYWORDS: Manufacturing industry; Heckscher-Ohlin Theorem; ability bias hypothesis; labor force qualification. 


\section{INTRODUÇÃO: O TEOREMA DE HECKSCHER-OHLIN E A HIPÓTESE DO VIÉS DE HABILIDADE}

Segundo Kuznets (1973), uma das fontes da mudança estrutural em uma economia é a mudança em sua posição competitiva no comércio internacional. Esta, por sua vez, pode surgir através de um processo de intensificação da abertura comercial e financeira, como a que ocorreu em países desenvolvidos, a partir de meados da década de 1980, e em países em desenvolvimento, a partir do final da década de 1980.

A intensificação da abertura comercial que ocorreu em vários países neste período foi objeto de análise de vasta literatura no arcabouço da Economia Internacional. Autores como Wood $(1995,1994,1991)$ e Leamer $(1996,1994,1993)$ defenderam a tese de que a mudança no grau de abertura comercial entre países desenvolvidos e em desenvolvimento teria sido a principal causa do aumento das desigualdades salariais nos EUA e do aumento do desemprego na Europa e Japão. Esses autores, com base no teorema de Heckscher-Ohlin (H-O), argumentaram que os trabalhadores menos qualificados foram os principais prejudicados com as quedas de barreiras de importações tarifárias ou não tarifárias de produtos oriundos de países como China e Índia.

Esse teorema estabelece que a abertura comercial leva um país a se especializar na produção daquele bem cuja fabricação é intensiva no fator de produção abundante domesticamente. Essa especialização levaria a um deslocamento da produção, com um consequente crescimento da demanda do fator abundante em detrimento do escasso na economia.

Desse modo, considerando como fatores de produção o trabalho qualificado e o não qualificado, a elevação da abertura comercial em países desenvolvidos, que são abundantes em trabalhadores qualificados, aumentaria a demanda relativa por estes. Já no caso de países em desenvolvimento que, em geral, possuem abundância relativa de mão-de-obra não qualificada, ocorreria o oposto. Como resultado, o processo de intensificação da abertura comercial deveria elevar a desigualdade salarial nos países desenvolvidos, tendo um efeito contrário naqueles em desenvolvimento.

Contudo, estudos empíricos constatam que o hiato salarial entre os trabalhadores qualificados e não qualificados tem aumentado tanto em economias desenvolvidas quanto em economias em desenvolvimento ${ }^{1}$. Depreende-se, dessa maneira, que vem ocorrendo uma elevação na demanda relativa por trabalhadores qualificados nos dois

\footnotetext{
Para economias desenvolvidas ver, por exemplo, Sachs e Shatz (1994) e Leamer (1996), que defendem o modelo de HO para explicar os crescentes diferenciais na demanda por trabalho. Para economias em desenvolvimento ver Arbache, Dickerson e Green (2004a, 2004b) e Wood (1997), em que os resultados estão mais próximos da hipótese do viés de habilidade.
} 
grupos de países. Portanto, alguns autores concluem que o teorema de $\mathrm{H}-\mathrm{O}$ é insuficiente para explicar os movimentos dos salários nas regiões, abrindo espaço para a hipótese do viés de habilidade da demanda por trabalho (Berman, Bound e Griliches, 1994; Desjonqueres et al., 1999; Menezes-Filho e Rodrigues Jr., 2003).

A hipótese do viés de habilidade pressupõe que a intensificação da abertura comercial, ao possibilitar uma maior difusão tecnológica entre as economias, facilita (barateia) a incorporação de métodos mais eficientes de produção nas firmas, inclusive em países em desenvolvimento. Esses novos métodos de produção, por sua vez, demandam mão de obra mais qualificada, o que eleva o diferencial de salário entre os trabalhadores qualificados e não qualificados (Menezes-Filho e Rodrigues Jr., 2003). Por outro lado, a maior concorrência externa forçaria as firmas a reagirem com maior eficiência produtiva, mais qualidade e maior diferenciação do produto, reforçando ainda mais a demanda por mão de obra qualificada. Em geral, estudos empíricos associam esta hipótese à implementação da informática e da microeletrônica nas rotinas de trabalho. Para o caso brasileiro, Giovannetti e Menezes-Filho (2005) encontraram evidências de que o processo de abertura comercial esteve associado à elevação da demanda relativa por trabalho qualificado, em um estudo considerando o setor industrial, entre $1990 \mathrm{e}$ 1998, o que favorece a hipótese do viés de habilidade. Machado e Moreira (2001) também encontram resultados que a abertura comercial, entre 1993 e 1997, favoreceu a demanda por trabalhadores qualificados, mas esses efeitos foram pouco expressivos.

Apesar das duas teorias não serem concorrentes, elas apontam para o mesmo sentido no caso de países desenvolvidos (aumento na demanda relativa dos trabalhadores mais qualificados), enquanto os efeitos destacados por ambas agem em direção opostas quando se considera o grupo de países em desenvolvimento.

Tendo em vista as diferentes teorias expostas anteriormente, o presente estudo analisa as fontes de deslocamento da força de trabalho brasileira e da determinação salarial, entre 1994 e 2008, com especial ênfase na indústria de transformação. A questão chave a ser analisada é se os aumentos de escolaridade verificados nos postos de trabalho ocorreram devido às mudanças na demanda provenientes das alterações ocorridas no grau de abertura comercial de acordo com a dotação de fatores da economia brasileira em relação aos seus parceiros comerciais, pelo maior grau de competitividade, pressionando a contratação de trabalhadores mais qualificados e/ou simplesmente pelo crescimento da oferta de trabalhadores qualificados.

Para verificar isso, lança-se mão de análises de decomposição de variáveis relativas à escolaridade dos trabalhadores. A aplicação dessa metodologia com base nas teorias mencionadas anteriormente, aplicadas em nível setorial e também em nível das firmas para o caso brasileiro, é uma das grandes contribuições do presente estudo em relação à literatura que trata do tema, sendo a análise possível a partir da utilização dos micro- 
dados da Relação Anual de Informações Sociais (RAIS), da Secretaria de Comércio Exterior (SECEX) e da Pesquisa Industrial Anual (PIA). No presente estudo, ao considerar conjuntamente a hipótese do viés de habilidade, o teorema $\mathrm{H}-\mathrm{O}$ e o comportamento salarial de acordo com os diferentes níveis de escolaridade, foi também possível verificar com mais precisão os efeitos de programas governamentais de universalização do nível de ensino fundamental e elevação de alunos matriculados nos níveis de ensino médio e superior na qualificação dos trabalhadores brasileiros, sendo outra contribuição importante do artigo, além de atualizar os dados em relação a estudos anteriores para a maior parte da primeira década dos anos 2000. A importância em se estender essa análise até 2008 ocorre pela expressiva evolução das exportações e importações brasileiras nos anos 2000, além de ser um período onde os programas governamentais voltados ao aumento da escolaridade dos brasileiros podem ser sentidos com mais força no mercado de trabalho em relação aos anos 1990.

A questão da oferta de trabalhadores mais qualificados é relevante ante o referido esforço do governo em estimular a elevação da escolaridade nos diferentes níveis de ensino, os quais têm promovido aumentos da escolaridade da população brasileira sem precedentes. Para a análise da oferta, serão verificados elementos salariais, partindo-se da premissa de que os aumentos na oferta desse fator sem uma elevação proporcional de sua demanda tendem a deprimir os salários, mesmo em indústrias com sindicatos organizados.

Os resultados da análise empírica indicam que a hipótese do viés de habilidade é adequada para explicar os movimentos da demanda por qualificação apenas no caso em que consideramos exclusivamente os trabalhadores com nível superior completo e na análise realizada para as firmas. Entretanto, mesmo nesses casos, sua contribuição foi pequena, indicando que a elevação no nível de escolaridade dos trabalhadores ocorreu, principalmente, devido a fatores relacionados à elevação da oferta. Portanto, a elevação da escolaridade dos trabalhadores dentro de cada segmento industrial brasileiro está muito mais relacionada a uma elevação da oferta decorrente de programas governamentais do que da demanda por trabalhadores mais qualificados que seriam decorrentes de processos produtivos mais complexos. Em relação aos fatores estruturais, os resultados são condizentes com as predições do teorema H-O para uma economia com abundância em trabalhadores pouco qualificados. Entretanto, seus efeitos também são pequenos quando comparamos com elementos da oferta de mão de obra qualificada.

Além da presente introdução, na próxima seção realizamos uma breve análise da evolução do comércio exterior no país. Na seção seguinte, utilizamos a análise de decomposição da escolaridade e dos salários médios dos trabalhadores segundo setores de atividade e de acordo com as firmas dentro de cada setor. Por fim, apresentamos as conclusões. 


\section{EVOLUÇÃO DO COMÉRCIO EXTERNO BRASILEIRO}

Esta seção busca identificar a evolução do comércio externo brasileiro a partir de 1988 e os impactos prováveis na demanda por qualificação da força de trabalho. Para isso, utilizamos, primeiramente, os coeficientes de importação, de exportação e de corrente de comércio brasileiros. Adicionalmente, é realizada uma análise das evoluções das importações e exportações brasileiras, através do cálculo das razões matemáticas das exportações e importações brasileiras, entre blocos de países em desenvolvimento e desenvolvidos. Isto servirá de base para observar os padrões comerciais verificados no período, subsidiando a análise realizada no item 4 .

Inicialmente, o Gráfico 1 descreve as evoluções das exportações, das importações e da corrente de comércio total do Brasil como proporções do PIB. Foram utilizados dados do Bacen e da Secretaria de Comércio Exterior (SECEX).

\section{Gráfico 1 - Evolução dos coeficientes de exportação e importação no Brasil (1988-2008)}

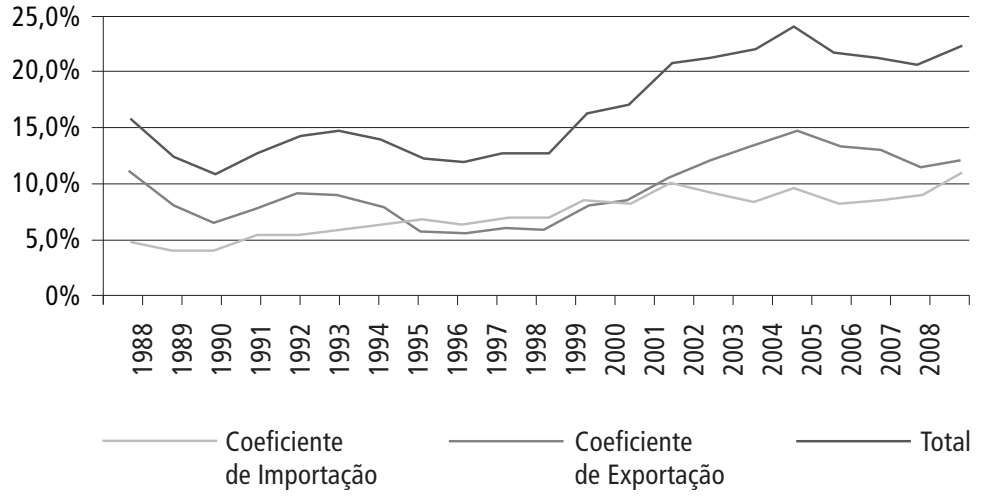

Fonte: Elaboração própria com base em dados do Boletim do Bacen, Secex e IPEA.

A partir do Gráfico 1, verificamos que o coeficiente de importação apresentou crescimento estável entre 1989 até 2001, respondendo ao processo de abertura ocorrida no país na década de 1990. A partir de então as importações como proporção do PIB declinaram até 2005 e voltaram a crescer, apresentando seu maior nível, dentro do intervalo estudado, em 2008. O coeficiente de importações passou de 4,95\%, em 1988, para 10,78\%, em 2008, sendo que a maior parte desse aumento ocorreu até 2001 . Depreende-se, dessa maneira, que o grau de participação das importações no PIB do Brasil mudou de patamar em função da abertura econômica no período, caracterizada pela redução das tarifas de importação e pela adoção de um câmbio valorizado. 
Já o coeficiente de exportações apresentou queda abrupta entre 1988 e 1990, elevou-se de 1990 a 1992, apresentando queda e estabilidade a partir de então, e passou a ganhar participação no PIB somente a partir de 1999, até atingir seu ápice, em 2004, quando chegou a 15\%. Se desconsiderarmos os anos de 1988 e 1989, período de elevada instabilidade econômica no país, constataremos que o coeficiente de exportações cresceu de 7,20\%, em 1990, para 14,52\%, em 2004. Entretanto, esse aumento se deve, sobretudo, à retomada do crescimento das exportações a partir de 1999. Após 2004, há um movimento de queda do coeficiente de exportações.

Podemos constatar que o processo de abertura juntamente com um processo de valorização cambial, ocorrido na década de 1990, reduziram as exportações e aumentaram as importações como proporções do PIB. Esse movimento foi acentuado com a adoção de um regime cambial mais rígido entre 1994 e o início de 1999. Contudo, a evolução dos coeficientes sofreu inflexão entre 1999 (no caso das exportações) e 2001 (para as importações). Antes de auferir como essas evoluções influenciaram a demanda por trabalho qualificado, é necessário observar o padrão de comércio externo no Brasil no período, de acordo com seus mercados de origem e destino.

Nesse sentido, no Gráfico 2, apresentamos as razões entre o valor das importações brasileiras provenientes de países em desenvolvimento (numerador) e de países desenvolvidos (denominador). O mesmo índice foi construído para as exportações. Os dados utilizados foram extraídos da Análise de Informações do Comércio Exterior Aliceweb, da SECEX. O critério utilizado para classificar os países como desenvolvidos ou em desenvolvimento foi o mesmo adotado pela SECEX.

Como o índice (razão das importações) é composto pela razão das importações provenientes dos países em desenvolvimento (numerador) sobre as importações oriundas dos países desenvolvidos (denominador), caso ele seja menor do que 1 (um) significa que a maior parte das importações tem como origem países desenvolvidos, sugerindo que o Brasil é um país abundante em mão de obra pouco qualificada de acordo com o teorema $\mathrm{H}-\mathrm{O}$. O mesmo raciocínio serve para a razão das exportações. De acordo com a evolução dessas razões apresentadas no Gráfico 2, as evidências sugerem que o país é intensivo em mão de obra pouco qualificada por apresentar razões menores do que 1 (um) em praticamente todo o período analisado. No entanto, a tendência é de reversão dessa situação, sobretudo a partir de 2008. 


\section{Gráfico 2 - Razões das importações e exportações de países em desenvolvimento e desenvolvidos (1989-2008)}

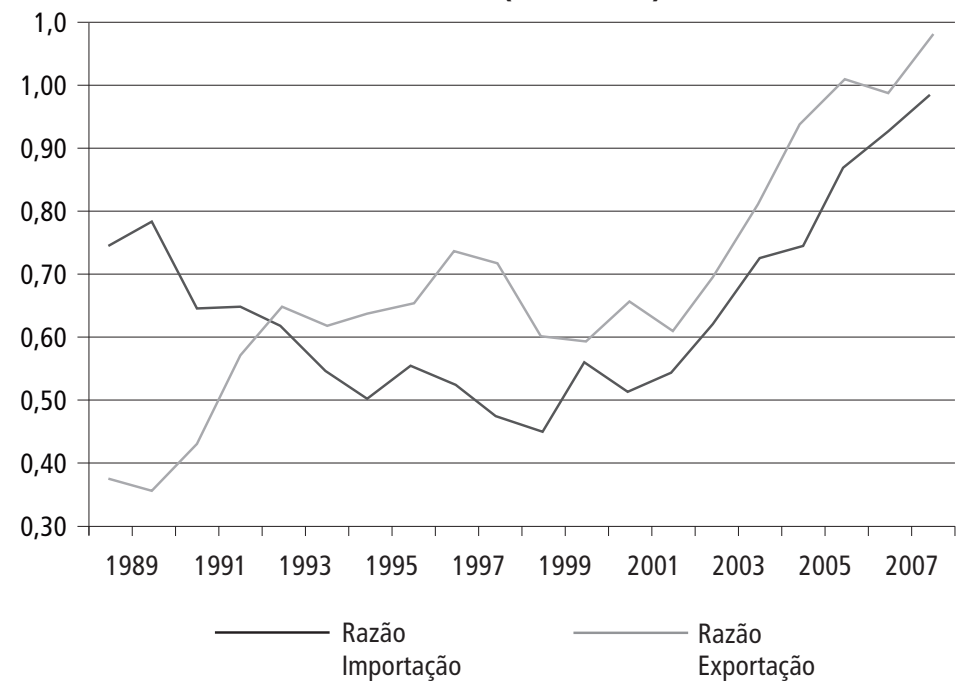

Nota: razão - países em desenvolvimento (numerador) / países desenvolvidos (denominador). Fonte: Elaboração própria com base em dados do Aliceweb/SECEX.

Analisando primeiramente as importações, é interessante perceber que no mesmo intervalo de tempo no qual o coeficiente de importações cresce, isto é, entre 1990 e 2001 (Gráfico 1), a razão das importações decresce. Desse modo, o Brasil passa a importar relativamente menos de países em desenvolvimento no mesmo período em que as importações ganham peso na economia. Pelo lado das importações, é razoável supor que o país passou por um processo de especialização produtiva com o processo de abertura econômica, aos moldes do modelo de HO, entre 1989 e 1999. Nesse intervalo, a economia importou mais e intensificou as importações de países desenvolvidos. Isso sugere que pelo lado das importações a demanda por mão de obra com alta qualificação nacional tenha declinado no período, sendo deslocada por produtos importados intensivos em mão de obra qualificada, de acordo com o teorema $\mathrm{H}-\mathrm{O}$.

Pelo lado das exportações o movimento é diferente entre 1989 e 1998, a razão das exportações cresce de 0,40 para cerca de 0,70 . Isto significa que o país passou a exportar mais para países em desenvolvimento no mesmo período em que o processo de abertura tarifária foi intensificado.

Esses movimentos podem ser explicados pelo perfil intermediário da indústria brasileira que, embora fosse, e ainda seja, periférica em termos mundiais, regionalmente se configura como líder. No entanto, como o coeficiente das exportações permaneceu abaixo de 1 (um), a demanda por trabalho pouco qualificado para produção dos produ- 
tos de exportação se manteve, mas de maneira menos intensa. Por outro lado, ocorreu uma modernização e especialização do setor produtivo doméstico em um nível intermediário, capaz de melhorar sua posição competitiva frente aos países vizinhos ${ }^{2}$. Esse processo de modernização e de especialização intermediária, por sua vez, é favorável à teoria do viés de habilidade. Os resultados do estudo de Campos, Hidalgo e Da Mata (2007) dão suporte a essa teoria, pois eles encontram evidências de que o processo de abertura comercial esteve associado à ampliação da desigualdade salarial na indústria de transformação brasileira, no período de 1992-1996.

Em consequência disso, a década de 1990 é ambígua em termos de demanda por trabalho qualificado, pois as duas principais teorias que a explicam apontam em sentidos opostos. Considerando o período a partir de 1999 e, principalmente, após 2002, podemos notar que ocorreu uma impressionante elevação relativa das exportações e importações para os países em desenvolvimento, o que reduz a demanda relativa por trabalhadores brasileiros pouco qualificados, de acordo com o teorema $\mathrm{H}-\mathrm{O}$. No entanto, é somente em 2008 que as razões de importações e exportações favorecem uma maior demanda por trabalhadores qualificados em relação aos pouco qualificados pelo canal do comércio internacional, pois foi o único ano do período analisado que a razão das exportações ficou acima de 1 (um), enquanto a razão das exportações ficou muito próxima de 1 (um).

Cabe destacar três pontos que podem ter influenciado nesse crescimento das razões de importações e exportações. O primeiro é a desvalorização cambial de 1999. O segundo foi a entrada da China na Organização Mundial do Comércio, em 2001, o que permitiu àquele país maior acesso aos mercados mundiais. O terceiro foi a reorientação da política externa do Brasil a partir de 2003, estimulando a intensificação das relações comerciais e políticas com países emergentes.

Em síntese, é de se esperar respostas ambíguas na demanda por trabalho qualificado no período de 1990 a 1999, em que a abertura tarifária possibilitou modernização do parque industrial nacional, pressionando a qualificação dos trabalhadores e, por outro lado, o câmbio valorizado inibiu as exportações industriais, dificultando o aumento da demanda por trabalhadores na indústria em geral e, em particular, daqueles mais qualificados. Com a flexibilização do câmbio a partir de 1999, é de se esperar que o processo de especialização intermediária da indústria brasileira tenha se reforçado, com impactos positivos na demanda por trabalhadores da indústria em geral, o que pressionaria o aumento da demanda pelos mais qualificados.

2 Castro (2012) expõe esse fenômeno de mudanças da indústria brasileira na década de 1990 e o seu caráter intermediário dentro do paradigma tecnológico da época, no artigo "Padrões comportamentais e estratégicos da indústria brasileira nos anos 1990". 


\section{ANÁLISES DE DECOMPOSIÇÃO E BASE DE DADOS}

\subsection{METODOLOGIA}

Na presente seção, apresentamos a metodologia da análise de decomposição. Esta é uma técnica já difundida em análises de variáveis econômicas. Por exemplo, Bond e Johnson (1992), Katz e Murphy (1992), Rossi Jr. e Ferreira (1999), Bonelli (2000), Fagerberg (2000), Carvalheiro (2003) e Holland e Porcile (2005) utilizaram-na para decompor as variações da produtividade nos setores manufatureiros em diversos países. Bernard e Jensen (1997), por sua vez, utilizaram esta técnica para decompor as variações das proporções de trabalhadores com ensino superior completo na manufatura americana e a proporção dos seus salários na folha salarial, entre 1973 e 1987, utilizando dados setoriais e em nível da firma.

Seguindo Bernard e Jensen (1997), dada uma variável qualquer $X$, sua taxa de variação entre o tempo inicial, $t_{0}$ e o tempo final, $t_{1}, \Delta X / X_{t_{0}}$, pode ser decomposta em duas componentes distintas como estabelecido na equação 1, a seguir:

$$
\frac{\Delta X}{X_{t_{0}}}=\frac{1}{X_{t_{0}}}(\underbrace{\sum_{i=1}^{n} \Delta p_{i} \cdot \bar{X}_{i}}_{I}+\underbrace{\sum_{i=1}^{n} \bar{p}_{i} \cdot \Delta X_{i}}_{I I})
$$

Em que $X$ é a variável a ser decomposta (escolaridade média dos trabalhadores ocupados na indústria de transformação, por exemplo); o índice $i$ se refere a i-ésima atividade econômica, no caso das decomposições setoriais, ou a i-ésima firma, no caso das decomposições no nível da firma; $p_{i}$ é a participação do i-ésimo setor (ou firma) no emprego total. Os traços sobre $p$ e $X$ indicam as médias dos seus valores entre os anos inicial e final.

No primeiro termo entre parênteses (componente $I$ ), a proporção da participação do setor varia $(\Delta p)$, enquanto que o nível de escolaridade (ou salário) é a média de $X_{t_{0}}$ e $X_{t_{1}}$. Portanto, esta componente captura a contribuição das mudanças da estrutura setorial no nível médio de escolaridade (ou salário). Se esse termo for positivo, significa que aqueles setores (ou firmas) que ganharam participação no emprego total possuem valores de $\bar{X}$ maiores que a média dos setores (ou firmas).

Já o segundo termo entre parênteses (componente $I I$ ) fixa a proporção do emprego na média dos dois anos e varia a escolaridade (ou salário). Neste caso, a componente captura a contribuição dos aumentos de escolaridade ou salário internos aos próprios setores ou firmas.

De acordo com o teorema de $\mathrm{H}-\mathrm{O}$, supondo que o país seja abundante em mão de obra pouco qualificada, o processo de intensificação da abertura comercial deveria favorecer os setores (ou firmas) que empregam um nível de qualificação da mão de obra menor do que a média da economia. Desse modo, estes deveriam ganhar participação 
no emprego total, fazendo com que a componente $I$, doravante entre, fosse negativa. Isto é, os efeitos da mudança estrutural deveriam agir no sentido de reduzir a escolaridade média dos trabalhadores ocupados na indústria de transformação.

Caso o viés de habilidade seja adequado à realidade brasileira, no período, a componente II, doravante intra, deveria ser positiva. Isto é, o processo de elevação no grau de abertura comercial deveria levar a um aumento na contratação de trabalhadores qualificados de forma a contribuir positivamente com o nível de escolaridade média. Certamente os segmentos que sofrem maior concorrência do setor externo, ou seja, os dos bens comercializáveis, deveriam elevar mais do que proporcionalmente a sua demanda por mão de obra qualificada.

Pelo viés de habilidade, poderíamos esperar ainda que nos períodos em que os setores (ou empresas) mais elevaram a demanda por qualificação dos seus funcionários foram aqueles em que eles pagaram salários maiores, em média. Portanto, uma elevação da escolaridade média dos trabalhadores na componente intra juntamente com uma correlação positiva com a componente intrassalarial favorecem a hipótese do viés de habilidade.

Por outro lado, se a correlação for negativa, sugere que aumentos da escolaridade nas firmas não estão associados a aumentos salariais, indicando a existência de um processo de elevação da oferta de qualificação da mão de obra sem o devido acompanhamento da demanda.

\subsection{BASE DE DADOS}

A base de dados utilizada para as decomposições em nível setorial foi formulada a partir dos dados da RAIS para os anos de 1994, 1997, 2000, 2003, 2005, 2006 e 2008. Para sua compilação foram tabuladas: (i) a escolaridade média dos empregados; (ii) a proporção de graduados sobre o total de empregados; (iii) o número médio de salários mínimos dos empregados; e (iv) a proporção da folha dos graduados sobre a folha total. Esses resultados foram verificados para todo o conjunto da Indústria de Transformação (Seção D para CNAE 95 e Seção C para CNAE 2.0), e para os setores desagregados, de acordo com as classes de atividade da Indústria de Transformação (CNAE Classe -5 dígitos).

Os salários reais foram calculados multiplicando-se o número médio de salários mínimos de dezembro de cada ano, da RAIS, pelo salário mínimo real de dezembro do ano correspondente, calculado pelo IPEADATA.

A amplitude temporal da amostra ficou restrita a disponibilidade de dados no momento da elaboração do artigo. Ainda, o lapso temporal entre um e outro ano tabulado não foi homogêneo em função da alteração da CNAE 95 para a CNAE 2.0. Em função disso, a amostra é trienal entre 1994 e 2003 e bienal a partir de 2003 até 2008. 
Já a base de dados utilizada para as decomposições no nível da firma constituiu-se da compilação de microdados oriundos da PIA do IBGE, RAIS e SECEX, para os anos de 1999 a 2005. As variáveis selecionadas para as decomposições foram: (i) a escolaridade média dos empregados; (ii) a proporção de graduados sobre o total de empregados; e (iii) o número médio de salários mínimos reais dos empregados.Não estava disponível a proporção dos salários dos graduados na folha de pagamento da firma. Os resultados foram desagregados ao nível da firma, e separados entre exportadoras e o total. Além disso, a amplitude temporal foi determinada pela disponibilidade dos dados e a periodicidade anual para o cálculo das variações foi determinada pela alta rotatividade de empresas da base.

\section{DECOMPOSIÇÕES DAS VARIAÇÕES DA ESCOLARIDADE E DOS SALÁRIOS}

\subsection{DECOMPOSIÇÕES EM NÍVEL SETORIAL}

Na Tabela 1, apresentamos os resultados da decomposição da escolaridade média dos trabalhadores da indústria de transformação e de seus salários médios. Para isso, utilizamos as atividades econômicas das classificações CNAE 1.0 - 5 dígitos (1994 a 2005) e CNAE 2.0 - 5 dígitos (2006 a 2008) ${ }^{3}$. Para anos anteriores a 1994 não havia dados CNAE disponíveis. Os resultados estão apresentados na Tabela 1.

Tabela 1 - Decomposição da variação da escolaridade média e do salário médio real da indústria de transformação (1994-2008)

\begin{tabular}{|c|c|c|c|c|c|c|}
\hline \multirow{2}{*}{ Período } & \multicolumn{3}{|c|}{ Escolaridade Média } & \multicolumn{3}{|c|}{ Salário Médio } \\
\hline & Intra & Entre & Total & Intra & Entre & Total \\
\hline 1994-1997 & 5,69 & $-0,28$ & 5,41 & 11,44 & $-2,79$ & 8,65 \\
\hline $1997-2000$ & 7,90 & $-0,01$ & 7,89 & $-8,50$ & $-3,07$ & $-11,57$ \\
\hline $2000-2003$ & 7,62 & $-1,14$ & 6,48 & $-1,40$ & $-1,28$ & $-2,68$ \\
\hline 2003-2005 & 3,95 & $-0,05$ & 3,90 & 0,38 & 0,17 & 0,55 \\
\hline $2006-2008^{1}$ & 3,25 & 0,13 & 3,38 & 4,65 & 0,74 & 5,39 \\
\hline \multirow{2}{*}{ Correlação } & \multicolumn{2}{|c|}{ Intra } & \multicolumn{2}{|c|}{ Entre } & \multicolumn{2}{|c|}{ Total } \\
\hline & \multicolumn{2}{|c|}{$-0,54$} & \multicolumn{2}{|c|}{0,20} & \multicolumn{2}{|c|}{$-0,75$} \\
\hline
\end{tabular}

Notas: Decomposição segundo CNAE 1.0 (5 dígitos). Os salários foram calculados multiplicando-se o número médio de salários mínimos de dezembro de cada ano, disponível na RAIS, pelo salário mínimo real de dezembro do ano correspondente, calculado pelo IPEA. Assim, os dados obtidos já estão em valores reais.

Fonte: Elaboração própria com base em dados da RAIS.

\footnotetext{
3 Optou-se por não realizar a decomposição entre os anos em que a CNAE foi alterada (2005 e 2006). Do contrário, poderia haver distorção nos resultados, uma vez que a correspondência entre a CNAE 1.0 e a CNAE 2.0 não é direta.
} 
Os resultados da Tabela 1 mostram, através dos sinais negativos da componente entre que, de 1994 a 2005, os segmentos que apresentaram níveis de escolaridades dos trabalhadores acima da média da indústria de transformação perderam participação no emprego total do setor. Apenas entre 2006 e 2008 essa tendência se reverteu. Apesar da baixa magnitude desses componentes, esses resultados estão de acordo com o que seria esperado pelo teorema de $\mathrm{H}-\mathrm{O}$ (ver Gráficos 1 e 2). Tais resultados são próximos aos obtidos por Arbache e Corseuil (2004) que analisaram o efeito da liberalização comercial sobre a estrutura de emprego e salário na indústria manufatureira entre 1987 a 1998, com resultados indicando que o processo de abertura comercial teve pouco impacto sobre a estrutura do emprego e sobre os prêmios salariais interindustriais.

Por outro lado, cada um dos segmentos apresentou acréscimos da escolaridade média de seus trabalhadores. Isto é, em média, ocorreu uma elevação da escolaridade da mão de obra dentro de cada segmento da economia. Observa-se ainda que a componente predominante foi a intra, ao passo que a entre foi pouco representativa da variação total da escolaridade, em todos os períodos analisados, sendo quase sempre negativa. Considerando a variável escolaridade, Menezes-Filho e Rodrigues Jr. (2003) também encontram efeitos consideravelmente maiores para a componente intra em relação à componente entre, no período 1981-1997. No entanto, para o período 1992-1997, a componente entre foi praticamente zero (ligeiramente positiva). As possibilidades para explicar essa discrepância nos resultados dos autores com os do presente estudo é que eles separaram os trabalhadores qualificados e não qualificados de acordo com os anos de escolaridade (11 anos), além dos autores utilizarem a indústria como um todo no exercício de decomposição e o emprego de diferentes bases de dados (PNAD ao invés da RAIS).

Como apontado anteriormente, uma possibilidade é que a contribuição positiva e mais relevante da componente intra esteja associada à maior demanda por qualificação inerente ao novo paradigma tecnológico em difusão a partir da década de 1990 (isto é, estaria relacionado à hipótese do viés de habilidade), caso ela seja acompanhada por uma elevação salarial. No entanto, como pode se verificar na última linha da Tabela 1 , a correlação dos componentes intra foi negativa no período analisado. Isto é, nos períodos em que se observaram os maiores aumentos de escolaridade média dos trabalhadores em cada setor ocorreu, concomitantemente, uma queda dos seus salários médios reais. Assim, essa evidência vai contra a hipótese do viés de habilidade.

Por sua vez, as componentes entre educacional e salarial apresentam correlação positiva, mas pequena. Isto é, a mudança estrutural ocorreu no sentido de reduzir a escolaridade média dos trabalhadores e com efeitos negativos sobre a média de seus salários reais, como esperado pelo teorema $\mathrm{H}-\mathrm{O}$ visto que os segmentos com maiores 
salários e onde os trabalhadores possuem maior nível de escolaridade deveriam perder participação no processo de abertura comercial devido à elevação da demanda externa por produtos intensivos em trabalho pouco qualificado e ao aumento da oferta de bens importados intensivos em trabalho qualificado.

Para tentar minimizar o efeito do aumento da escolaridade dos trabalhadores devido à implantação de programas governamentais, as decomposições foram realizadas apenas com trabalhadores graduados (mais qualificados). Isto se justifica porque grande parte do aumento da escolaridade média dos trabalhadores brasileiros, no período analisado, ocorreu no nível de ensino médio completo.

A análise realizada acima para o conjunto de empregados registrados na RAIS na indústria de transformação é reproduzida e apresentada na Tabela 2 para a classe de trabalhadores com o nível superior completo. As decomposições contemplam as variáveis “proporção de graduados na indústria de transformação" e "proporção dos salários dos graduados na folha salarial da indústria de transformação". Foram utilizadas, mais uma vez, as classes de atividade econômica CNAE 1.0 e 2.0 - 5 dígitos.

Tabela 2 - Decomposição da variação da proporção de graduados e da proporção de seus salários reais médios (1994-2008)

\begin{tabular}{c|c|c|c|c|c|c}
\hline \multirow{2}{*}{ Período } & \multicolumn{3}{|c|}{ Proporção de Graduados } & \multicolumn{3}{c}{ Proporção dos Salários } \\
\cline { 2 - 8 } & Intra & Entre & Total & Intra & Entre & Total \\
\hline $1994-1997$ & 11,14 & $-2,12$ & 9,02 & 10,26 & $-0,54$ & 9,72 \\
\hline $1997-2000$ & 9,38 & $-4,39$ & 4,99 & 15,38 & $-0,44$ & 14,94 \\
\hline $2000-2003$ & 16,75 & $-2,31$ & 14,45 & 15,67 & $-0,61$ & 15,06 \\
\hline $2003-2005$ & $-0,13$ & $-0,35$ & $-0,48$ & 2,26 & $-1,27$ & 0,99 \\
\hline $2006-2008^{1}$ & 10,23 & 0,61 & 10,84 & 5,25 & $-0,92$ & 4,33 \\
\hline \multirow{2}{*}{ Correlação } & \multicolumn{3}{|c|}{ Intra Entre } & \multicolumn{2}{c}{ Total } \\
\cline { 2 - 7 } & \multicolumn{3}{|c|}{0,77} & \multicolumn{3}{c}{0,80} \\
\hline
\end{tabular}

Nota: Decomposição segundo CNAE 1.0 (5 dígitos).

Fonte: Elaboração própria com base em dados da RAIS.

Os resultados da Tabela 2 apresentam certa similaridade com os da Tabela 1. A quarta coluna da Tabela 2 (Total) mostra que a proporção de graduados na indústria de transformação aumentou na maior parte do período analisado, com exceção do período 2003-2005. O aumento acumulado ao longo de todo o período foi de 44,5\%, indicando que houve um aumento substancial de trabalhadores com ensino superior completo na indústria de transformação.

Por outro lado, os resultados das componentes entre indicam que no período de 1994 a 2005 os setores que empregavam proporções maiores de graduados, em relação 
à média da indústria de transformação, perderam participação no emprego total. Ou seja, a mudança estrutural da indústria de transformação ocorreu no sentido de reduzir a quantidade de trabalhadores com nível superior completo, estando de acordo com o teorema $\mathrm{H}-\mathrm{O}$.

Os resultados apresentados na Tabela 2 também indicam que a componente entre teve menor peso absoluto na explicação dos movimentos de aumento da qualificação dos empregados na indústria de transformação brasileira, em período recente. Adicionalmente, a componente entre exibiu efeitos negativos mais expressivos em relação aos resultados apresentados na Tabela 1, com exceção do subperíodo 2006-2008. Assim, esses resultados fornecem evidência de que as forças do comércio internacional expostas pelo teorema de $\mathrm{H}-\mathrm{O}$ tiveram alguma relevância na explicação da mudança na escolaridade dos trabalhadores mais qualificados. É importante ressaltar que esse efeito negativo se reduziu conforme ocorreu uma elevação da proporção do comércio internacional com países em desenvolvimento, o que seria de se esperar pelo teorema de H-O (ver Gráfico 2).

Hernández (2008), através de uma análise para o mercado de trabalho brasileiro entre 1989 e 1998, também encontrou evidências de que o processo de liberalização comercial sobre o mercado de trabalho no Brasil, isolando os choques tecnológicos, expandiu o emprego nas indústrias intensivas em trabalho menos qualificado, com consequentes reduções na desigualdade de distribuição de renda, sendo esta mensurada pelo prêmio salarial por qualificação. No entanto, o autor encontra efeitos mais relevantes do processo de abertura comercial sobre a elevação da demanda relativa por trabalhadores menos qualificados do que no presente estudo.

Outro estudo que aponta para a relação positiva existente entre abertura comercial e redução da desigualdade salarial nas diferentes regiões brasileiras é aquele elaborado por Lima e Barreto (2007), considerando o período de 1990 a 1998 . No entanto, os autores encontraram evidências de que o processo de abertura comercial estimulou a exportação de manufaturados no Sul e Sudeste do país, enquanto que na região Nordeste, as exportações de produtos básicos foram as mais beneficiadas. Machado e Moreira (2001) também encontram indícios de que o processo de abertura comercial pode ter sido importante na elevação da demanda por trabalhadores menos qualificados, no período 1990-1993. No entanto, entre 1993 e 1997, os deslocamentos da demanda por trabalho intrassetoriais possuem efeitos dominantes em 
relação aos efeitos entre os setores, favorecendo, ainda que de forma pouco expressiva, a hipótese do viés de habilidade ${ }^{4}$.

No presente estudo, a componente intra apresentou contribuições positivas em quatro dos cinco subperíodos, indicando que cada segmento da indústria de transformação aumentou sua proporção de graduados. Como a correlação entre as componentes intraeducacional e intrassalarial é positiva e elevada, os resultados apresentados na Tabela 2 favorecem a hipótese de viés de habilidade, pelo menos em relação aos trabalhadores com nível superior completo. No entanto, a comparação adequada é entre o crescimento da proporção de graduados em relação à proporção dos seus salários. Isto é, se a proporção de graduados no quadro de funcionários de um setor aumenta, seria de se esperar que o total dos salários também se elevasse. Se a proporção dos salários aumentar mais do que a proporção de empregados, significa que os graduados estão, em média, experimentando aumentos salariais reais.

Através dos resultados apresentados na Tabela 2, chega-se a um aumento acumulado de $56,3 \%$ de graduados e 58,4\% para seus salários, via componente intra, ao longo de todo o período. Essas evidências dão suporte à hipótese do viés de habilidade para os trabalhadores mais qualificados. No entanto, sua importância é pequena.

\subsection{DECOMPOSIÇÃO CONSIDERANDO FIRMAS}

O teorema H-O se refere a mudanças na demanda por produtos das empresas domésticas em função de uma maior exposição externa. No entanto, em muitos casos ocorrem deslocamentos da demanda dentro dos próprios setores, segmentos ou indústrias. Neste caso, a análise em nível setorial seria insuficiente. Se este for o caso, a análise setorial pode levar a erros de interpretação, conforme apontam Bernard e Jensen (1997). A análise setorial parte do pressuposto que, a partir de um estímulo estrutural qualquer, as empresas de um mesmo setor irão reagir de maneira mais ou menos homogênea, ou seja, supõe-se que as mesmas possuem estruturas e dotações semelhantes de fatores. Entretanto, a heterogeneidade das respostas entre as firmas de um mesmo setor pode ter peso importante na análise dos deslocamentos da demanda por trabalhadores qualificados.

\footnotetext{
4 Em uma análise para o período 1989-2010, Hidalgo e Feistel (2013) encontraram evidências que estão de acordo com o teorema de H-O. No entanto, os autores não focaram o mercado de trabalho considerando as alterações na demanda por trabalhadores qualificados e não qualificados. Eles chegaram à conclusão de que os dados favorecem esse teorema ao observarem uma tendência em longo prazo de elevação, na pauta de exportações brasileira, da participação dos produtos intensivos em recursos naturais e queda daqueles intensivos em capital e trabalho, enquanto que, na pauta de importações, a tendência é de redução da participação de recursos intensivos em recursos naturais e elevação daqueles intensivos em capital.
} 
Seguindo Bernard e Jensen (1997), foram realizadas decomposições considerando as empresas da indústria de transformação como unidades de análise para verificar estas hipóteses. Os dados utilizados são uma compilação de dados da PIA, RAIS e SECEX. As decomposições foram realizadas ano a ano, pois subperíodos maiores iriam levar a exclusão de boa parte das empresas que não sobreviveram a todo período analisado ${ }^{5}$.

A Tabela 3 apresenta os resultados das decomposições da escolaridade média para o total de empresas da amostra e para as exportadoras de 1999 a 2005, anos em que os dados estavam disponíveis para as firmas.

Tabela 3 - Decomposição da variação da escolaridade média e dos salários médios na indústria de transformação ao nível da firma (1999-2005)

\begin{tabular}{c|c|c|c|c|c|c|c}
\hline \multirow{4}{*}{ Variável } & \multirow{2}{*}{ Período } & \multicolumn{3}{|c|}{ Exportadoras } & \multicolumn{3}{c}{ Todas } \\
\cline { 2 - 8 } & & Intra & Entre & Total & Intra & Entre & Total \\
\hline \multirow{4}{*}{$\begin{array}{c}\text { Escolaridade } \\
\text { média }\end{array}$} & $1999-2000$ & 2,99 & $-0,25$ & 2,74 & 2,79 & $-0,32$ & 2,47 \\
\cline { 2 - 8 } & $2000-2001$ & 3,22 & $-0,38$ & 2,84 & 2,79 & $-0,29$ & 2,49 \\
\cline { 2 - 8 } & $2001-2002$ & 2,73 & 0,10 & 2,83 & 2,51 & 0,14 & 2,65 \\
\cline { 2 - 8 } & $2002-2003$ & 2,94 & $-1,08$ & 1,86 & 2,94 & $-0,76$ & 2,18 \\
\cline { 2 - 8 } & $2003-2004$ & 2,01 & $-0,56$ & 1,45 & 2,22 & $-0,33$ & 1,89 \\
\cline { 2 - 8 } & $2004-2005$ & 1,90 & $-0,40$ & 1,50 & 2,07 & $-0,03$ & 2,04 \\
\hline \multirow{5}{*}{$\begin{array}{c}\text { Salário } \\
\text { médio }\end{array}$} & $1999-2000$ & 1,80 & $-1,98$ & $-0,18$ & 1,74 & $-3,42$ & $-1,68$ \\
\cline { 2 - 8 } & $2000-2001$ & 3,95 & $-2,11$ & 1,83 & 3,91 & $-3,04$ & 0,87 \\
\cline { 2 - 8 } & $2001-2002$ & $-3,48$ & $-0,88$ & $-4,36$ & $-3,28$ & $-1,58$ & $-4,86$ \\
\cline { 2 - 8 } & $2002-2003$ & 3,41 & $-3,45$ & $-0,05$ & 3,33 & $-3,29$ & 0,04 \\
\cline { 2 - 8 } & $2003-2004$ & 4,07 & $-1,86$ & 2,21 & 4,04 & $-2,04$ & 2,00 \\
\hline \multirow{5}{*}{ Correlação } & 0,09 & 0,91 & $-0,35$ & 0,14 & 0,76 & $-0,76$ \\
\hline
\end{tabular}

Nota: A mostra consistiu de uma média anual de cerca de 100.000 empresas ao todo e cerca de 10.000 empresas exportadoras. Na linha correlação é apresentada a correlação entre as variáveis salário médio e escolaridade média.

Fonte: Elaboração própria com base em dados da RAIS, SECEX e PIA.

Verifica-se que, para os dois grupos de empresas, todas e exportadoras, os valores das componentes intra das escolaridades médias foram positivos e elevados, enquanto os das componentes entre foram negativos e relativamente pequenos. Isso mostra que a escolaridade aumentou no período em função dos seus aumentos internos às empresas.

5 As análises de decomposição pelos métodos até aqui utilizados devem ser realizadas para todas as empresas ao longo de todo o período. Caso uma empresa não esteja presente no ano inicial ou final ela deve ser excluída da análise. Firmas sem empregados registrados também foram excluídas. 
Por outro lado, aquelas que empregavam pessoal mais qualificado, em média, perderam participação no emprego total da indústria de transformação.

Através dos valores das decomposições salariais observa-se, ainda, preponderância das componentes intra, além das contribuições positivas para as mesmas. As componentes entre, por sua vez, apresentaram resultados mais expressivos aos observados na decomposição da escolaridade média. Porém, mais uma vez, eles foram negativos, mostrando que as firmas que pagavam salários maiores perderam participação no emprego da indústria de transformação, em média.

Desse modo, chegamos novamente ao resultado de que essa transformação estrutural agiu no sentido de estimular a demanda por trabalhadores com menores níveis de escolaridade e com menores níveis salariais, o que está de acordo com o teorema de H-O. A correlação intra foi positiva, mas baixa. Esse resultado sugere que nos momentos em que ocorreu uma elevação da qualificação dos trabalhadores, também houve uma elevação salarial, o que está de acordo com a hipótese do viés de habilidade. No entanto, a baixa correlação mostra que esse efeito não foi muito importante para o Brasil, no período em questão.

Duas últimas decomposições foram realizadas. Ambas utilizando a variável proporção de graduados no quadro de funcionários (Tabela 4). As decomposições salariais não foram feitas, pois as informações salariais dos graduados não estavam disponíveis na base de dados.

Tabela 4 - Decomposição da variação da proporção de graduados na indústria de transformação no nível da firma, exportadoras e total (1999-2005)

\begin{tabular}{c|c|c|c|c|c|c|c}
\hline \multirow{2}{*}{ Variável } & \multirow{2}{*}{ Período } & \multicolumn{3}{|c|}{ Exportadoras } & \multicolumn{3}{c}{ Todas } \\
\cline { 2 - 8 } & & Intra & Entre & Total & Intra & Entre & Total \\
\hline \multirow{4}{*}{$\begin{array}{c}\text { Proporção de } \\
\text { Graduados }\end{array}$} & $1999-2000$ & 3,68 & $-1,02$ & 2,65 & 3,50 & $-3,77$ & $-0,28$ \\
\cline { 2 - 8 } & $2000-2001$ & 4.07 & $-1,48$ & 2,59 & 4,44 & $-4,23$ & 0,21 \\
\cline { 2 - 8 } & $2001-2002$ & 7,64 & 0,40 & 8,04 & 7,08 & $-2,02$ & 5,07 \\
\cline { 2 - 8 } & $2002-2003$ & 5,89 & $-3,32$ & 2,57 & 7,18 & $-4,92$ & 2,27 \\
\cline { 2 - 8 } & $2003-2004$ & 1,65 & $-2,49$ & $-0,84$ & 2,13 & $-3,47$ & $-1,34$ \\
\cline { 2 - 8 } & $2004-2005$ & 3,17 & $-2,33$ & 0,84 & 3,91 & $-3,21$ & 0,69 \\
\hline
\end{tabular}

Fonte: Elaboração própria com base em dados da RAIS, SECEX e PIA.

Observa-se, também nos resultados apresentados na Tabela 4, preponderância da componente intra em relação à componente entre, exceto no período 2003-2004 (exportadoras e todas) e 1999-2000 (todas). Seus valores são todos positivos e ligeiramente maiores para o total de empresas do que somente para exportadoras.

Podemos notar, ainda, que a componente entre apresentou resultados bastante expressivos, principalmente quando se consideram todas as empresas. Seus valores foram 
negativos, mostrando que as empresas que empregavam parcelas maiores de graduados perderam participação no Emprego total, em média. Esses resultados dão suporte ao teorema de $\mathrm{H}-\mathrm{O}$, considerando a hipótese de que o Brasil é intensivo em mão de obra pouco qualificada seja válida, o que parece ser o caso de acordo com os dados apresentados no Grafico 2.

\section{CONCLUSÕES}

As análises de decomposição setoriais para as escolaridades médias indicam que a hipótese do viés de habilidade seria adequada para explicar os movimentos da demanda por qualificação na indústria de transformação brasileira apenas no caso em que consideramos exclusivamente os trabalhadores com nível superior completo. Entretanto, sua contribuição foi pequena, indicando que a elevação no nível de escolaridade dos trabalhadores ocorreu, principalmente, devido a fatores relacionados à elevação da oferta de trabalho com maior escolaridade.

Em relação aos fatores estruturais, os sinais negativos da componente entre, em nível setorial, foram condizentes com as predições do teorema $\mathrm{H}-\mathrm{O}$ para uma economia com abundância em trabalhadores pouco qualificados, que se abre ao comércio com países abundantes em mão de obra qualificada. Ou seja, os efeitos destacados pelo teorema de $\mathrm{H}-\mathrm{O}$ têm certo poder de explicação para o comportamento do nível de escolaridade dos trabalhadores da indústria de transformação. No entanto, a pequena importância da componente entre também indica que os efeitos destacados pelo teorema de $\mathrm{H}-\mathrm{O}$ não são tão relevantes para explicar as mudanças ocorridas nessa variável, embora o efeito seja mais importante quando consideramos a análise realizada no nível das firmas.

É importante notar que uma elevação da escolaridade dos trabalhadores da indústria de transformação não seria condizente com os efeitos destacados pelo teorema de $\mathrm{H}-\mathrm{O}$, pois se o país é intensivo em mão de obra não qualificada, seria de se esperar uma elevação relativa nos salários desses trabalhadores e, como consequência, uma elevação da quantidade dos trabalhadores pouco qualificados na economia brasileira. Apenas com a utilização do método da decomposição foi possível verificar que os efeitos enfatizados pelo teorema de $\mathrm{H}-\mathrm{O}$ tiveram certa importância na economia brasileira mesmo com esse fenômeno da elevação média da escolaridade dos trabalhadores da indústria de transformação.

De uma forma geral, a explicação mais adequada para se entender a variação no nível de escolaridade dos trabalhadores da indústria brasileira está relacionada aos fatores da oferta e não da demanda. O fato da maior parte da elevação da escolaridade média ser proveniente da componente intra juntamente com uma redução salarial dos 
trabalhadores ou uma elevação pequena indicam isso, apesar dos efeitos destacados por $\mathrm{H}-\mathrm{O}$ e pela hipótese do viés de habilidade estarem presentes no período analisado.

A partir desse ponto seria importante analisar se a queda real ou a pequena elevação dos salários dos trabalhadores da indústria de transformação brasileira juntamente com a elevação do nível de escolaridade dos trabalhadores está refletindo a formação excedente de pessoas mais qualificadas ou se esse efeito é um fenômeno puramente quantitativo e que não está alterando a qualificação, de fato, dos trabalhadores da indústria de transformação.

Por fim, os resultados apresentados indicam que, nas duas últimas décadas, a economia brasileira vem evoluindo no sentido de se tornar menos intensiva em mão de obra pouco qualificada.

\section{REFERÊNCIAS}

ARBACHE, J. S.; CORSEUIL, C. H. Liberalização comercial e estruturas de emprego e salário. Revista Brasileira de Economia, v. 58, n. 4, p. 485-505, 2004.

ARBACHE, J. S.; DICKERSON, A.; GREEN, F. Assessing the stability of the inter-industry wage structure in the face of radical economic reforms. Economics Letters, v. 83, n. 149.155, 2004a.

ARBACHE, J. S.; DICKERSON, A.; GREEN, F. Trade liberalization and wages in developing countries. The Economic Journal, v. 114, p. 73-96, 2004 b.

BERMAN, E. J.; BOUND, J.; GRILICHES, Z. Changes in the demand for skilled labour within U.S. manufacturing: evidence from the Annual Survey of Manufacturers. Quarterly Journal of Economics, v. 109, 1994.

BERNARD, A. B.; JENSEN, J. B. Exporters, skill upgrading, and the wage gap. Journal of International Economics, v. 42, p. 3-31, 1997.

BONELLI, R. Ganhos de produtividade na economia brasileira na década de 90: um retrato de corpo inteiro. Edição 20 de Seminários DIMAC. Rio de Janeiro: IPEA/DIMAC, 2000.

BOUND, J.; JOHNSON, G. Changes in the Structure of Wages in the 1980s: An evaluation of alternative explanations. American Economic Review, v. 82, p. 371-392, 1992.

CARVALHEIRO, N. Uma decomposição do aumento da produtividade do trabalho no Brasil durante os anos 90. Revista de Economia Contemporânea, v. 7, n. 1, p. 81-109, jan./jun. 2003.

CAMPOS, M. F. S. S.; HIDALGO, A. B.; DA MATA, D. Abertura, comércio intra-indústria e desigualdade de rendimento: uma análise para a indústria de transformação brasileira. Nova Economia, v. 17, n. 2, p. 275-306, 2007.

CASTRO, A. B. "Padrões Comportamentais e estratégicos da indústria brasileira nos anos 1990”. In: CASTRO, A. C.; CASTRO, L. B. (Orgs.) Do desenvolvimento renegado ao desafio sinocêntrico: reflexões de Antonio Barros de Castro sobre o Brasil. Rio de Janeiro: Elsevier, 2012, p. 99-125. 
DESJONQUERES, T.; MACHIN, S.; VAN REENEN, J. Another nail in the coffin? Or can the trade based explanation of changing skill structures be resurrected? Scandinavian Journal of Economics, v. 101, 1999.

FAGERBERG, J. Technological progress, structural change and productivity growth: a comparative study. Structural Change and Economic Dynamics, v. 11, p. 393-411, 2000.

GIOVANNETTI, B.; MENEZES-FILHO, N. A. Liberalização comercial e demanda por trabalho qualificado no Brasil. In: Encontro Nacional de Economia, 23, Natal, RN, 2005.

HERNÁNDEZ, B. M. Liberalização comercial, mudanças tecnológicas e mercado de trabalho no Brasil. Pesquisa e Planejamento Econômico, v. 38, n. 2, p. 197-225, 2008.

HIDALGO, A. B.; FEISTEL, P. R. Mudanças na estrutura do comércio exterior brasileiro: uma análise sob a ótica da teoria de Heckscher-Ohlin. Estudos Econômicos, v. 43, n. 1, p. 79-108, 2013.

HOLLAND, M.; PORCILE, G. "Brecha tecnológica y crecimiento en América Latina”. In: CIMOLI, M. (Ed.) Heterogeneidad estructural, asimetrías tecnológicas y crecimiento en América Latina. Santiago: BID-CEPAL, 2005.

KATZ, L. F.; MURPHY, K.M. Changes in relative wages 1963-1987: Supply and demand factors. Quarterly Journal of Economics, v. 107, p. 35-78, 1992.

KUZNETS, S. Modern economic growth: findings and reflections. American Economic Review, v. 63 , p. $247-258,1973$.

LEAMER, E. E. “Wage effects of a U.S.-Mexican free trade agreement”. In: GARBER, P. M. (Ed.) The Mexico-U.S. Free Trade Agreement. Cambridge, Mass.: MIT Press, 1993, p. 57-125.

LEAMER, E. E. Trade, wages and revolving-door ideas. Working Paper, National Bureau of Economic Research, Cambridge, n. 4716, 1994.

LEAMER, E. E. Wage inequality from international competition and technological change: theory and country experience. American Economic Review, v. 86, 1996.

LIMA, F. S.; BARRETO, F. A. Abertura comercial, dotação de fatores produtivos e desigualdade de rendimentos no Brasil: 1990-1998. Revista Economia, Brasília, v. 8, n. 1, p. 65-92, 2007.

MACHADO, A. F.; MOREIRA, M. M. Os impactos da abertura comercial sobre a remuneração relativa do trabalho no Brasil. Revista de Economia Aplicada, v. 5, n. 3, p. 491-517, 2001.

MENEZES-FILHO, N. A.; RODRIGUES Jr. M. Tecnologia e demanda por qualificação na indústria brasileira. Revista Brasileira de Economia, v. 57, n. 3, p. 569-603, 2003.

ROSSI JR., J. L.; FERREIRA, P. C. Evolução da produtividade industrial brasileira e abertura comercial. Texto para Discussão, IPEA, Rio de Janeiro, n. 651, 1999.

SACHS, J. D.; SHATZ, H. J. Trade and jobs in U.S. manufacturing. Brookings Papers on Economic Activity, v. 1, 1994.

WOOD, A. How much does trade with the South affect workers in the North? World Bank Research Observer, v. 6, p. 19-36, 1991. 
WOOD, A. North-south trade, employment and inequality: changing fortunes in a skill-driven world. Oxford: Clarendon Press, 1994.

WOOD, A. How trade hurt unskilled workers. The Journal of Economic Perspectives, v. 9, n. 3, 1995.

WOOD, A. Openness and wage inequality in developing countries: The Latin American challenge to East Asian conventional wisdom. The World Bank Economic Review, v. 11, n. 1, p. 33-57, 1997. 